\author{
도시공원의 필수 설계요소 추출 \\ - 2017년 서울시 공원이용 만족도 조사의 결과 분석을 바탕으로 - \\ 이재호* · 김순기 ${ }^{* *}$ \\ "텍사스 A\&M 대학교 여가공원관광학과 박사후연구원 · "단국대학교 녹지조경학과 강사

\section{Extraction of Essential Design Elements for Urban Parks - Based on the Analysis of 2017 Satisfaction Survey of Park Use in Seoul -}

\author{
Lee, Jae Ho* $\cdot$ Kim, Soonki \\ *Postdoc, Dept. of Recreation Park, and Tourism Sciences, Texas A\&M University \\ *t Lecturer, Dept. of Landscape Architecture, Dankook University
}

\begin{abstract}
The aim of this study is to provide foundational knowledge of how to enhance the user satisfaction of urban parks. The study seeks to identify essential factors that influence user satisfaction and to provide better design strategies for future park design as well as the reorganization of existing ones.

To measure user satisfaction, this study used factor analysis to extract essential factors - facility conditions, landscape and scenery, safety, and kindness - by using data from a survey conducted by the city of Seoul in 2017. We then used a regression analysis to infer causal relationships between the independent variables and the dependent variables (user satisfaction). The results revealed that the most significantly and positively related variable to user satisfaction in urban parks was safety $(\beta=0.276, p<.000)$, followed by landscape and scenery $(\beta=0.230, p<.000)$, facility conditions $(\beta=0.215$, $p<.000)$, and kindness $(\beta=0.208, p<.000)$. The results indicate that, for future urban park designs, planners and designers should prioritize the issues of safety by adopting crime prevention through environmental design (CPTED). In addition, planners and designers of future park designs should heavily weigh the selection and provision of relevant facilities for the intended use as well as well-arranged and well-managed plants and trees. Based on the results of IPA analysis, the most urgent improvement elements appeared to be the factor of kindness; however, the impact of kindness influencing user satisfaction was less important than that of safety and landscape and scenery in the urban park design processes.

This study demonstrates that to maximize the user satisfaction of the urban park design processes and to provide more valuable spaces for users, it is necessary to secure park safety and to create well-composed landscape and scenery. Future research should provide more detailed and specified urban park design strategies corresponding with the importance of the factors identified in this study.
\end{abstract}

Key Words: Satisfaction of Urban Parks, Safety of Parks, Landscapes and Scenery, Kindness, Regression Analysis

Corresponding author: Soonki Kim, Lecturer, Dept of Landscape Architecture, Dankook University, Cheonan 31116, Korea, Tel.: +82-41-550-3630, E-mail: soongi@gmail.com 


\section{국문초록}

본 연구는 도시 내 공원을 새로이 조성하거나 기존의 도시공원을 재정비할 때 공원의 이용만족도를 높이기 위한 필수적인 설계요소를 추출함으로써 계획 및 설계에 필요한 기초자료를 제공하기 위한 목적으로, 서울시가 2017년 시행한 공원이용만족도 조사의 결과를 분석하여 도시공원의 중요설계요소를 도출하고자 하였다.

연구는 설문조사를 바탕으로 시설관리상태, 조경 및 경관, 공원 안전성, 친절도 등의 항목을 중요 설계요소로서 추출한 후 회귀분석을 통하여 각 항목과 공원이용만족도 간의 관계를 분석하였다. 연구 결과, 공원 안전성 $(\beta=0.276$, $p<.000)$, 조경 및 경관( $\beta=0.230, p<.000)$, 시설관리상태 $(\beta=0.215, p<.000)$, 친절도 $(\beta=0.208, p<.000)$ 순으로 영향력을 미치는 것으로 나타났다. 연구결과에 따르면 공원 안전성의 확보를 위하여 추후 도시공원의 설계에서 범죄예방환경설계(CPTED) 등의 적극적인 활용이 요구되며, 적절하며 균형 있는 수경시설과 수목의 배치 및 관리를 통한 짜임새 있는 조경 및 경관의 구성 또한 도시공원의 이용만족도를 높일 수 있는 매우 중요한 요소로서 추후 공원설계에서 매우 주의 깊게 다루어야 할 요소로 판단되었다. 이에 반해, 현 도시공원에서 가장 시급하게 개선되어야 할 요소로서 나타난 친절도의 경우, 추후 도시공원의 설계과정에서는 필수설계요소로서의 공원 안전성 및 조경 및 경관 요소에 비해 그 중요성이 적은 것으로 나타났다.

따라서 추후 도시공원의 설계과정에서 이용자 만족도를 최대화하고, 실제 이용자에게 보다 가치 있는 공간의 제공을 위해서는 공원 안전성 및 조경 및 경관 요소의 적절한 활용이 요구된다. 더 나아가, 향후 연구에서는 이 논문에서 밝혀진 요소들을 통한 보다 구체적이며, 세분화된 도시공원 디자인 전략을 제시할 필요가 있다.

주제어 : 도시공원만족도, 공원 안전성, 조경 및 경관, 친절도, 회귀분석

\section{I. 서론}

도시민의 삶의 질 향상을 위한 도시공원의 제공은 도시의 역 할 중 매우 중요한 위치를 차지하며, 오늘날 도시의 당연한 의 무로 자리 잡았다. 산업화와 도시화에 의한 대기의 매연문제와 도시 근로자의 주거환경 개선요구를 바탕으로 그 필요성이 크 게 대두된 도시공원은 오늘날보다 다양하고 복잡해진 환경문 제와 결부되며, 그 중요성을 더하고 있다. 더하여 오늘날 도시 공원은 단순히 도시의 환경문제의 해결만을 위한 수단이 아닌 도시공원을 둘러싼 다양한 담론들, 생태, 지역사회, 랜드스케이 프어바니즘, 민간참여, 도시재생 등 다양한 패러다임의 변화와 수용을 통해 보다 다양한 차원에서 도시민의 삶을 풍요롭게 만 드는 공간으로서 그 역할이 점점 더 중요해지고 있으며, 그 결 과, 다양한 레크리에이션 활동을 비롯하여 지역주민의 여가활 용공간으로서 중요한 위치를 차지하고 있다.

이러한 이유로 오늘날 도시공원에는 보다 다양한 기능이 요 구되고 있으며, 그러한 요구를 수용하기 위해 보다 다양한 기 능적, 디자인적 접근이 시도되고 있다. 그러나 아직까지 많은 도시공원이 매우 형식적이며, 미흡한 시설의 제공으로 실제 도 시민과 이용자의 다양한 기능 요구를 수용하지 못하고 있는 실 정이다(Park and Kim, 2010).

도시공원을 포함한 대부분의 도시의 공공공간에 보다 적절 한 기능성을 부여하고, 이용을 극대화하기 위해서는 그 공간에
서 이루어지는 인간행태에 관한 세밀한 관찰을 통해 이용자와 이용자의 행태의 공간적, 사회적 관계를 체계적으로 파악하고, 이를 설계에 반영하는 노력이 요구된다(Zeisel, 1981). 그러나 현실적으로 모든 도시공원의 설계 과정에서 세밀한 이용자의 관찰이 가능한 것은 아니다. 예를 들어 오늘날 많은 지자체에 서 시행하고 있는 전혀 다른 용도의 공간을 도시공원이나 공공 오픈스페이스로 전환하는 도시재생사업과 같은 경우, 기존 이 용자가 공원 이용자가 아니라는 한계 등이 있어 기존 이용자의 행태 관찰을 통한 공간적, 사회적 관계 분석 및 이를 반영한 공 원설계의 근원적인 어려움이 존재한다.

본 연구는 이러한 어려움을 극복하고 도시공원 내에 보다 가 치 있는 시설의 제공을 위해 도시공원의 설계에서 차용하여야 하는 요소가 무엇인지를 알아보고자 서울시내 23개 공원 이용 객을 대상으로 이루어진 공원이용만족도 설문조사의 결과를 분석하였다.

\section{II. 이론적 고찰}

우리나라의 경우, r국토의 계획 및 이용에 관한 법률」및 r도 시공원 및 녹지 등에 관한 법률, 등을 통해 도시공원의 정의와 필요성뿐 아니라, 도시공원이 마땅히 제공하여야 할 각종 기능 들에 대해 정의한다. 특히 r국토의 계획 및 이용에 관한 법률」 에서는 공원을 도시의 기반시설의 하나로 취급함으로써 공원 
을 도로나 하수도와 마찬가지로 도시 내 반드시 갖추어져야 하 는 가장 기본적인 시설로 간주한다(2조 6 항). 또한, 도시공원 및 녹지 등에 관한 법률」 2 조 4 항을 통해 도시공원이 갖추어야 할 공원시설로서 1) 도로 또는 광장, 2) 화단·분수·조각 등 조경시설, 3) 휴게소, 긴 의자 등 휴양시설, 4) 그네 · 미끄럼틀 등 유희시설, 5) 테니스장 - 수영장 - 궁도장 등 운동시설, 6) 식 물원 · 동물원 · 수족관 · 박물관 · 야외음악당 등 교양시설, 7 ) 주차장 - 매점·화장실 등 이용자를 위한 편익시설, 8) 관리사 무소·출입문 - 울타리 · 담장 등 공원관리시설, 9) 그밖에 도시 공원의 효용을 다하기 위한 시설로서 국토교통부령이 정하는 시설 등을 지정하고 있다. 즉, 도시공원은 도시의 중요 기반시 설로서 도시민에게 편안한 휴식과 다양한 레크리에이션을 제 공하기 위한 다양한 조경, 휴양, 유희, 운동, 교양, 편익 시설 등을 갖춘 공간이며, 이러한 현대 도시공원의 성격을 만족시키 기 위한 다양한 기능을 가진 공간과 설계요소가 오늘날 도시공 원에 등장하고 있다.

도시공원을 둘러싼 담론 및 이용자의 요구, 행태 등이 다양 해지면서 이러한 다양성을 반영하여 도시공원과 관련된 연구 또한 여러 가지 주제와 함께 지속적으로 이어지고 있다. 그 중 특히 도시공원의 이용자에 대한 행태 및 만족도를 조사하고, 그 자료를 분석하는 방식의 연구가 지속적으로 진행되고 있으 나, 이러한 연구는 대부분 공원이용자의 이용행태 및 만족도를 통해서 공원관리의 시사점 도출 및 이용 활성화로 귀결되는 경 우가 다수였으며(Bae and Kim, 2013; Kim et al., 2010; Lee, 2009; Seo and Kim, 2000), 그 외에도 도시공원의 부족성, 입 지, 확충 등 도시 차원에서의 공원 공급에 관한 연구(Kim, 2014; Kim et al., 2011; Lee et al., 2009; Lee and Lee, 2010) 또한 다수 확인되었다. 또한, 이용만족도와 관련하여 특히 도시 공원의 안전성에 대하여 집중적으로 분석한 연구가 다수 발표 되어(Cho and Yeon, 2014; Kang, 2011; Lee and Lee, 2009; Rho, 1995; Won and Jeong, 2001) 도시 공원에서 공원 안정성 에 대한 관심이 매우 높음을 확인하였다.

도시공원에 관한 다양한 연구 중 도시공원에 관한 만족도 조 사를 바탕으로 공원의 시설물에 대한 관리방안과 조성방안 및 추후 개발방향 등의 시사점을 도출한 연구 중 본 연구의 주제 및 연구방법 등과 관련하여 관련성을 가지는 연구도 다수 확인 되었다. Joo(2008)는 국내의 대표적인 공원(일산호수공원, 여 의도공원, 하늘공원, 양재천, 올림픽공원, 선유도공원, 평화의 공 원, 서울광장, 청계천, 파리공원, 서울숲, 길동자연생태공원 등) 을 설문조사를 통해 각 공원의 시설만족도, 이용행태, 경관이미 지, 선호도 등을 분석하여 5 개의 유형으로 구분하여 도시공원 의 유형화를 위한 방안을 제안하였다. Moon(2001)은 서울시 도시공원을 대상으로 지역구조와 공간적 특색을 규명하고, 도 시공원 이용자의 행태적 특성과 이용만족도 결정요인을 분석 하여 서울시의 환경친화적 도시경관의 구축을 위한 도시공원
정책을 제안했다. 특히 Moon은 이용만족도를 분석하여 수종다 양성, 대기수준, 레크리에이션 공간으로서의 적정성, 심미적 만 족도, 흥미도, 인상성 등의 설계에서 차용 가능한 요소를 추출 하여 제시하였다. 또한, $\operatorname{Im}(1991)$ 은 도시공원 이용만족도의 조 사결과를 바탕으로 도시공원시설과 이용만족도의 가설적 인과 모형을 만들고, 이를 바탕으로 도시공원의 개발방향 설정에 관 한 연구를 하였다. 그러나 이 연구는 공원의 개별적 시설보다 는 공원의 접근성과 이용 빈도 등을 통해 공원개발의 방향성을 제시한 것으로 본 연구와 그 과정은 유사하나, 결론도출의 방 향성에서 차별성을 갖는다.

본 연구에서는 서울시의 23 개 공원(서울숲, 응봉공원, 보라매 공원, 양재 시민의 숲, 천호공원, 길동생태공원, 율현공원, 남산, 낙산, 간데메, 중랑캠핑숲, 북서울 꿈의 숲, 창포원, 용산가족공 원, 경춘선숲길, 월드컵공원, 여의도공원, 선유도공원, 푸른수목 원, 경의선숲길, 서서울호수공원, 독립공원, 어린이대공원)을 대 상으로 실시된 공원만족도 설문조사의 데이터를 분석하여 추 후 서울시내 공원을 신설하거나, 기존공원의 재정비 시 설계과 정에서 고려해야 할 중요 설계요인을 추출하여 도시공원, 특히 서울의 도시공원의 설계과정에 이용자의 요구와 만족도에 근 거한 기초자료를 제공하고 반영할 수 있도록 하고자 한다.

\section{III. 연구범위 및 방법}

\section{1. 자료수집}

본 연구는 도시공원의 설계 시 고려해야 할 필수요소 추출을 위하여 서울시에서 설문 조사를 실시한 자료를 이용하였다. 대 상자는 2017년에 서울시의 공원을 이용하는 서울 시민들을 대 상으로 하였고, 이용자들의 공원 서비스 만족도를 파악하기 위 해 설문조사를 실시한 결과를 이용 분석하였다. 설문조사는 전 문설문 조사기관(와이즈인 컴퍼니)을 이용하여 실시되었고, 공 원 선정은 서울시와의 협의에 의해서 선정되었다. 선정 기준은 서울시(동부, 중부, 서부 공원녹지사업소)에서 직접 운영 관리 하고 있는 23개 공원에서 이루어졌으며, 설문 대상자는 만 15 세 이상 공원 이용 시민을 대상으로 하였다. 표본수 산정은 공 원의 규모, 이용객수 등을 종합적으로 고려하여 서울시 공원녹 지정책과에서 임의로 정하였다(예, 50만 제곱미터 이상 또는 이용객수 1 천만 명 이상: 200 명, 20 만명 이상 또는 5 백만 명 이 상: 150명, 기타: 100 명).

자료 수집은 공원 방문객을 대상으로 매 $\mathrm{K}$ 번째 해당하는 대 상자를 선정하여 조사하는 방식을 취하였고, 주중과 주말의 비 율을 약 4:6 정도로 설정하였다. 면접원이 한사람씩 직접 설문 을 요청하였고, 구조화된 설문지를 이용하여 자기기입식(Selfadministered questionnaires) 설문이 이루어졌다. 자료수집 기 간은 7 월 1 일에서 30 일이었고, 유효표본수는 3,000 명을 대상으 
로 하였으며, 매점과 같은 편의시설이 없는 공원이나 이를 이 용하지 않았다고 응답한 대상자는 결측치로 처리하고 분석에 이용하였다.

\section{2. 설문지 구성 및 변수의 측정}

설문지 문항 구성에서 개인적 특성에는 응답자의 성별, 연령 대, 직업에 관한 문항을 포함하였으며, 공원이용만족도에 영향 을 미치는 구성요소의 중요도 및 만족도에 관한 분야별 항목은 시설관리상태, 조경 및 경관, 공원 안전성, 친절도의 4 개 척도 로 구성되었다(Table 1 참조). 각 척도별 세부 항목은 서울시 에서 매년 공원 이용객들이 체감할 수 있는 주요 사항을 정리 하였고, 다년간 실증적 경험을 바탕으로 전문설문조사기관과 의 협의를 통해 세부 항목을 만들었다. 시설관리상태는 산책로 공중화장실, 휴식공간, 음수대, 매점 및 음식점, 쓰레기통, 안내 판 총 7 문항으로 구성되었고, 조경 및 경관에 대한 항목은 조경 시설 및 수경시설, 자연 친화성, 시설물 조화 총 3 문항으로 구 성되었다. 공원 안전성은 야간 조명상태, 불량청소년, 취객, 노 숙인 관리, 애완동물 이용수칙 준수, 통행, 시설물, 공중화장실, 공원안전 이용수칙, 어린이 놀이시설 총 8 문항으로 이뤄졌고, 친절도 척도는 근무 직원의 친절도, 판매시설 직원 친절도, 판 매시설 가격 만족도 총 3 문항으로 구성되었다. 마지막으로 공 원이용의 전반적인 만족도를 측정하는 문항으로 설문지를 완 성하였다. 각 분야별 세부 항목의 측정방식으로는 5 점 리커트 척도(1점-전혀 그렇지 않다. 7점-매우 그렇다)를 이용하였다.

\section{3. 분석 방법}

수집된 자료는 SPSS Statistics ver. 21.0 프로그램을 활용하여 다음과 같이 분석하였다. 첫째, 공원 이용자의 인구통계학적 특 성을 파악하기 위한 빈도분석(frequency analysis)을 실시하였 다. 둘째, 구성 요소들 간의 상대적인 중요도와 만족도 비교를 위해서 IPA 분석(Importance-Performance Analysis)을 실시하 였다. 셋째, 다중회귀분석을 위해 각 척도별로 요인분석을 실시 하였다. 넷째, 요인 분석한 값과 전반적 만족도간의 다중회귀분 석을 실시하여 만족도에 미치는 척도별 영향력을 조사하였다.

\section{IV. 결과 및 고찰}

\section{1. 이용자 일반 특성}

표본의 인구통계적 특성을 살펴보면 남성, 여성 동일하게 1,500 명씩 조사되었고, 연령대별로는 ‘60대 이상’이 23.3\%로 고 령자의 비율이 높은 것으로 나타났으며, 반대로 '15 19세' 젊은 층의 이용률이 $9.6 \%$ 로 적게 나왔다. 직업의 경우, '주부'가 가 장 높았으며(25.4\%), 그 다음으로는 학생(19.5\%) 그리고 사무 직(15.8\%) 순이었다. 그 외 인구통계적 특성은 Table 2 와 같다.

\section{2. 수정-IPA 분석결과}

기존의 많은 연구에서 직접 중요도 측정의 문제를 지적하였 듯이 이 연구에서는 각 척도의 세부 항목과 전반적 만족도 간

Table 2. Respondents' socio-demographic characteristics

\begin{tabular}{c|c|c|c}
\hline \multicolumn{2}{|c|}{ Division } & Frequency $(\mathrm{N})$ & Percentage(\%) \\
\hline \multirow{4}{*}{ Gender } & Male & 1,500 & 50.0 \\
\cline { 2 - 4 } & Female & 1,500 & 50.0 \\
\hline \multirow{4}{*}{ Age } & $15 \sim 19$ & 289 & 9.6 \\
\cline { 2 - 4 } & $20 \mathrm{~s}$ & 466 & 15.5 \\
\cline { 2 - 4 } & $30 \mathrm{~s}$ & 488 & 16.3 \\
\cline { 2 - 4 } & $40 \mathrm{~s}$ & 539 & 18.0 \\
\cline { 2 - 4 } & 50s & 520 & 17.3 \\
\hline \multirow{5}{*}{ Occupation } & 60s or more & 698 & 23.3 \\
\cline { 2 - 4 } & Self-employed & 257 & 8.6 \\
\cline { 2 - 4 } & Sales and service & 156 & 5.2 \\
\cline { 2 - 4 } & Skilled worker & 45 & 1.5 \\
\cline { 2 - 4 } & Industrial employee & 22 & 0.7 \\
\cline { 2 - 4 } & Office worker & 474 & 15.8 \\
\cline { 2 - 4 } & Manager & 48 & 1.6 \\
\cline { 2 - 4 } & Professional & 258 & 8.6 \\
\cline { 2 - 4 } & Housewife & 761 & 25.4 \\
\cline { 2 - 4 } & Student & 585 & 19.5 \\
\cline { 2 - 4 } & Others & 394 & 13.1 \\
\hline
\end{tabular}

Table 1. Contents of questionnaire

\begin{tabular}{|c|c|c|c|}
\hline Category & & Contents & Measurement type \\
\hline Personal characteristics & & Gender, age, occupation & Categorical type \\
\hline Facility conditions & $\mathrm{F} 1$ & Trail, toilet, rest area, drinking fountain, cafeteria, trash can, sign board & \multirow{5}{*}{$\begin{array}{l}\text { Continuous type } \\
\text { (Likert scale) }\end{array}$} \\
\hline Landscape, scenery & $\mathrm{F} 2$ & Landscape and waterscape, natural affinity, harmonious with other facilities & \\
\hline Safety & F3 & $\begin{array}{l}\text { Night light, disorder, pet regulations, pedestrian traffic, facility, toilet, } \\
\text { park regulations, children playground }\end{array}$ & \\
\hline Kindness & $\mathrm{F} 4$ & Park employee, cafeteria employee, price satisfaction & \\
\hline \multicolumn{2}{|c|}{ Overall satisfaction } & Overall satisfaction & \\
\hline
\end{tabular}


의 상관계수 값을 통하여 그 계수를 $100 \%$ 의 비율로 산정해 중 요도로 사용하였으며(Matzler et al., 2004), 만족도 산정은 시 민들이 각 항목에 대해 평가한 점수의 평균값을 사용하였다. X 축과 Y축 영역을 나누는 기준은 만족도와 중요도의 각각 평균 을 구하여 사용하였고, 공원 이용 만족도에 영향을 미치는 21 개 항목이 그래프에 표시되었다. 공원 이용 만족도에 따른 수 정-IPA 결과는 다음 Figure 1, Table 3과 같다.

1 사분면(유지강화)에서는 전반적으로 '조경 및 경관'에 대한 항목들을 중요하게 인식하고 있고, 만족도 또한 높았다는 점으 로 보아, 조경 및 경관 요소는 도시공원의 추후 설계과정에서 공원을 구성하는 중요 설계요소로써 인식하고 구성해야 함이 필요하다고 판단되었다. 2사분면(중점개선)에 있어서 매점/음 식점과 관련된 항목들이 중요하다고 인식되나, 만족도가 높지 않게 나타났다. 구체적으로 매점/음식점 시설 관리 상태와 판 매시설 직원의 친절도에 관해 이용자들의 만족도가 높지 않았 고, 또한 공원 근무 직원의 친절도도 높지 않아 공원 이용객의 만족을 위해서는 친절도 교육 등을 통하여 서비스적 마인드를 갖게 하여 불만을 시급히 개선할 필요가 있다고 판단된다. 또 한, 추후의 공원설계 과정에서는 이러한 결과를 적극적으로 반 영하여 매점/음식점 시설의 관리 용이성 및 직원 친절도의 향 상을 가져올 수 있는 설계요소의 반영이 필요한 것으로 분석된 다. 어린이 놀이시설 안전성에 대한 중요성이 가장 높게 나온 점은 주부 응답자의 비중이 높았기 때문으로 판단된다. 3 사분 면(점진개선)에서는 공원 이용 안전성에 대한 항목이 많이 분 포되어 있었다. 예를 들어, 공원 내 야간 조명 상태, 불량 청소 년, 취객, 노숙인 관리, 애완동물 이용수칙 준수, 그리고 통행 안전성에 있어서 응답자들의 만족도가 높지 않게 조사되었다. 영역 분류상 이 항목들이 3 사분면에 위치했지만, 중요도는 상 대적으로 높게 측정된 점은 공원의 안전성이 다른 중요 항목과

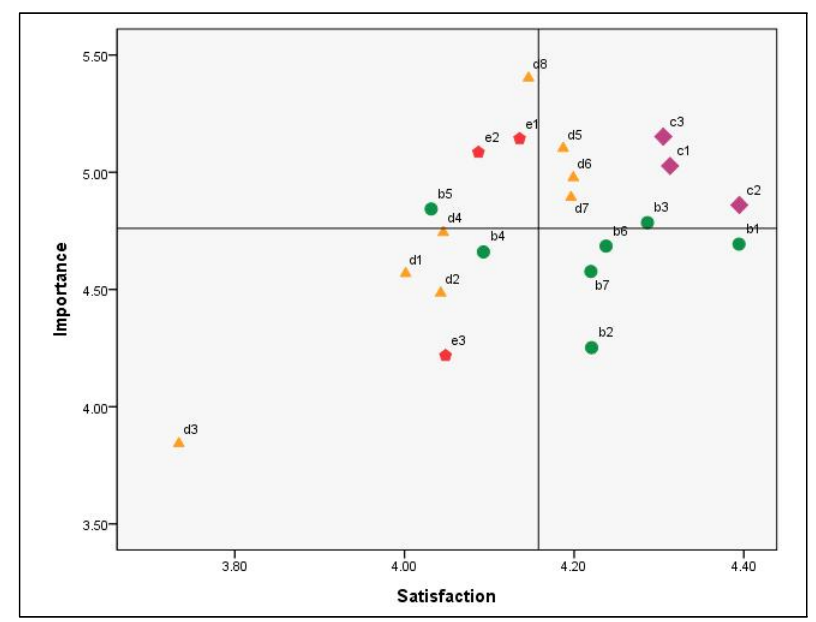

Figure 1. Modified-IPA matrix

Legend: Facility conditions $\triangle$ Landscape, scenery
Table 3. The results of modified-IPA analysis

\begin{tabular}{|c|c|c|c|c|}
\hline Qaudrant & $\#$ & Item & Importance & Satisfaction \\
\hline \multirow{7}{*}{$\begin{array}{l}\text { Keep up } \\
\text { the good } \\
\text { work } \\
\text { (I) }\end{array}$} & b3 & Rest area & 4.785 & 4.286 \\
\hline & $\mathrm{cl}$ & $\begin{array}{l}\text { Landscape and } \\
\text { waterscape }\end{array}$ & 5.027 & 4.313 \\
\hline & $c 2$ & Natural affinity & 4.860 & 4.395 \\
\hline & c3 & $\begin{array}{c}\text { Harmonious with other } \\
\text { facilities }\end{array}$ & 5.152 & 4.305 \\
\hline & $\mathrm{d} 5$ & Facility & 5.102 & 4.187 \\
\hline & $\mathrm{d} 6$ & Toilet & 4.977 & 4.199 \\
\hline & $\mathrm{d} 7$ & $\begin{array}{l}\text { Park regulations, } \\
\text { children playground }\end{array}$ & 4.894 & 4.196 \\
\hline \multirow{4}{*}{$\begin{array}{l}\text { Concentration } \\
\text { (II) }\end{array}$} & b5 & Cafeteria & 4.844 & 4.031 \\
\hline & $\mathrm{d} 8$ & Children playground & 5.402 & 4.146 \\
\hline & el & Park employee & 5.144 & 4.136 \\
\hline & e2 & Cafeteria employee & 5.085 & 4.087 \\
\hline \multirow{6}{*}{$\begin{array}{l}\text { Low priority } \\
\text { (III) }\end{array}$} & $\mathrm{b} 4$ & Drinking fountain & 4.660 & 4.093 \\
\hline & $\mathrm{d} l$ & Night light & 4.569 & 4.001 \\
\hline & $\mathrm{d} 2$ & Disorder & 4.485 & 4.043 \\
\hline & d3 & Pet regulations & 3.843 & 3.734 \\
\hline & $\mathrm{d} 4$ & Pedestrian traffic & 4.744 & 4.046 \\
\hline & e3 & Price satisfaction & 4.218 & 4.048 \\
\hline \multirow{4}{*}{$\begin{array}{c}\text { Possible } \\
\text { overkill } \\
\text { (IV) }\end{array}$} & b1 & Trail & 4.694 & 4.394 \\
\hline & b2 & Toilet & 4.252 & 4.221 \\
\hline & b6 & Trash can & 4.685 & 4.238 \\
\hline & b7 & Sign board & 4.577 & 4.220 \\
\hline
\end{tabular}

비교해 실질적인 이용자의 측면에서 동등하거나, 매우 중요한 요소로 분석 가능하며, 따라서 추후 도시공원의 설계에서 공원 의 안전성 확보가 매우 중요한 설계요소임을 확인할 수 있었다. 마지막으로, 4 사분면(지속유지)에는 공원시설관리와 관련된 항목들이 위치하였고, 대체로 공원 시설에 있어서 이용자들이 중요하다고 인식하는 것에 비해 만족도가 상대적으로 높았음 을 알 수 있다. 이는 공원의 설계과정에서 공원 시설 관리와 홍 보, 이용객들의 인식 개선 등을 전략적으로 추구한다면 전반적 인 공원 이용 만족도를 높일 수 있는 강점이 될 수 있다고 판 단된다.

\section{3. 탐색적 요인분석}

다중회귀분석을 실행하기 전 문항 타당성을 검증하기 위하 여 탐색적 요인분석을 실시하였다. 요인분석은 주성분 분석의 varimax 직각회전 방법을 사용하였으며, 구성요인을 추출하기 위해서 주성분 분석(principle component analysis)을 사용하였 고, 요인적 재치는 0.4 이상을 기준으로 하였다.

Table 4에서 보듯이, 각 척도별로 고유치 기준 값(Eigenvalues)이 1.0 이상으로 하나씩 추출되었고, 변수들 간의 적합 
도를 나타내는 $\mathrm{KMO}$ (Kaiser-Meyer-Olkin) 값은 모든 요인분 석에서 0.5이상으로 적합하다고 간주되었다(Kaiser, 1974). 마 지막으로, 각 요인별 신뢰계수는 모든 척도에서 0.8 이상으로 높게 나타나, 도출된 요인들의 통계적 신뢰성이 확보되었다. 탐 색적 요인분석을 통해 제거된 항목 없이 총 21개의 항목이 4 개 의 요인으로 구분되었다(Table 4 참조).

\section{4. 회귀분석}

Table 4. Factor analysis(principal component analysis)

\begin{tabular}{|c|c|c|c|c|c|c|c|}
\hline Construct & Items & Mean & Std. & Loadings & Eigenvalue & $\%$ of variance & Alpha \\
\hline \multirow{7}{*}{ Facility conditions } & Trail & 4.323 & .682 & .786 & 4.575 & 65.355 & .911 \\
\hline & Toilet & 4.143 & .815 & .793 & & & \\
\hline & Rest area & 4.194 & .781 & .811 & & & \\
\hline & Drinking fountain & 3.959 & .864 & .822 & & & \\
\hline & Cafeteria & 4.028 & .816 & .811 & & & \\
\hline & Trash can & 4.125 & .819 & .836 & & & \\
\hline & Sign board & 4.093 & .801 & .800 & & & \\
\hline \multicolumn{8}{|c|}{$\mathrm{KMO}=.926$, Chi-square $=5,727.733, d f=21, p<.000$} \\
\hline \multirow{3}{*}{ Landscape, scenery } & Landscape, waterscape & 4.313 & .716 & .911 & 2.519 & 83.977 & .904 \\
\hline & Natural affinity & 4.395 & .683 & .914 & & & \\
\hline & Harmonious with other facilities & 4.305 & .730 & .924 & & & \\
\hline \multicolumn{8}{|c|}{$\mathrm{KMO}=.754$, Chi-square $=5,795.896, d f=3, p<.000$} \\
\hline \multirow{8}{*}{ Safety } & Night light & 4.001 & .789 & .738 & 5.003 & 62.531 & .909 \\
\hline & Disorder & 4.044 & .880 & .760 & & & \\
\hline & Pet regulations & 3.726 & .970 & .645 & & & \\
\hline & Pedestrian traffic & 4.047 & .884 & .803 & & & \\
\hline & Facility & 4.192 & .740 & .840 & & & \\
\hline & Toilet & 4.192 & .770 & .823 & & & \\
\hline & Park regulations & 4.198 & .794 & .826 & & & \\
\hline & Children playground & 4.146 & .737 & .868 & & & \\
\hline \multicolumn{8}{|c|}{$\mathrm{KMO}=.934$, Chi-square $=13,606.893, d f=28, p<.000$} \\
\hline \multirow{3}{*}{ Kindness } & Park employee & 4.018 & .866 & .894 & 2.397 & 79.900 & .870 \\
\hline & Cafeteria employee & 3.945 & .872 & .933 & & & \\
\hline & Price satisfaction & 3.608 & .966 & .853 & & & \\
\hline
\end{tabular}

Table 5. Result of multiple regression analysis

\begin{tabular}{|c|c|c|c|c|c|c|c|}
\hline \multirow{2}{*}{ Dependent variable } & \multirow{2}{*}{ Independent variable } & \multicolumn{2}{|c|}{ Unstandardized } & \multirow{2}{*}{$\frac{\text { Standardized }}{\text { Beta }}$} & \multirow{2}{*}{$t$} & \multirow{2}{*}{ Sig. } & \multirow{2}{*}{ VIF } \\
\hline & & B & Std. error & & & & \\
\hline \multirow{5}{*}{$\begin{array}{c}\text { Overall } \\
\text { satisfaction }\end{array}$} & (Constant) & 4.114 & .015 & & 269.862 & .000 & \\
\hline & Facility conditions & .148 & .024 & .215 & 6.230 & .000 & 3.160 \\
\hline & Landscape, scenery & .149 & .020 & .230 & 7.582 & .000 & 2.440 \\
\hline & Safety & .191 & .022 & .276 & 8.621 & .000 & 2.705 \\
\hline & Kindness & .145 & .019 & .208 & 7.548 & .000 & 2.007 \\
\hline
\end{tabular}


을 확인하였다. 공원이용만족도 요인 중 전반적 만족에 가장 큰 영향을 미친 요인은 안전성 $(\beta=0.276, p<.000)$ 으로 나타났 으며, 조경 및 경관 $(\beta=0.230, p<.000)$, 시설관리상태 $(\beta=0.215$, $p<.000)$, 친절도 $(\beta=0.208, p<.000)$ 가 뒤를 이었다. 따라서 공원 이용만족도 요인들은 전반적 만족에 유의한 정 $(+)$ 의 영향을 미치는 것으로 확인되었다.

이상의 회귀분석 결과를 보면 안전성 요인이 전반적 만족도 에 가장 큰 영향을 미치고 있음을 알 수 있으며, 이를 통해 '공 원이용 안전성'이 추후 공원 설계에 가장 중요한 요소로서 작 용되어야 할 것으로 판단된다. 이는 위의 IPA 분석의 안전성 관련 항목들이 만족도가 낮게 나온 것과 연관이 있다고 볼 수 있다. IPA 분석 결과에서 안전성 항목 중 시설물 안전성, 공중 화장실 안전성, 공원안전 이용수칙, 어린이 놀이시설 안전성 항 목들의 중요성이 높게 나왔고, 그 외 만족도가 낮게 평가된 다 른 안전성 항목들(야간 조명상태, 불량청소년, 취객, 노숙인 관 리, 애완동물 이용수칙 준수, 통행 안전성)과 관련이 있다고 보 인다. 만족도가 낮게 나온 안전성 항목들은 IPA 분석 결과에서 는 분류상 3 사분면(점진 개선)에 위치하여 덜 중요하게 구분되 지만, Figure 1에서 보듯이 애완동물 이용수칙 준수를 제외한 나머지 세 영역 간 경계선 근처에 위치하고 있어 중요성이 낮 지 않음을 보여준다.

안전성 요인이 공원이용만족도에 가장 큰 영향이 미치는 것 으로 조사되었지만, 표준화 계수 비교를 보면 각 요인 간 상대 적인 영향력 차이가 그리 크지 않음을 확인할 수 있다. IPA 분 석에서 확인되었듯이 이용자들의 만족도가 높았던 '조경 및 경 관'과 '시설물관리상태' 요인은 공원이용만족도를 높이는데 중 요한 요인임을 확인하였다. 마지막으로, IPA 분석에서 '친절도' 와 관련된 만족도는 전반적으로 낮게 나왔지만, 다중회귀분석 결과 다른 요인에 비해서는 영향력이 작게 나왔다. 이는 이용 자들이 공원직원 및 판매시설 직원들의 친절도가 중요하다고 인식하지만, 공원이용만족도를 평가하는데 있어서 직접적인 영 향을 미치지는 않는다고 판단하였음을 볼 수 있다.

\section{V. 결론}

본 연구는 추후 공원을 신설하거나 재정비할 때 활용 가능한 기초자료를 제공하는 것을 목표로 서울시의 공원이용만족도 조사결과를 바탕으로 도시공원의 중요 설계요소를 추출하고자 하였다. 시설관리상태, 조경 및 경관, 공원 안전성, 친절도 등의 공원요소를 대상으로 한 설문조사의 결과를 회귀분석하여 도 출한 시사점은 다음과 같다.

1. 본 연구에서 설문조사의 항목에서 추출한 도시공원 설계 요소의 네 가지 요인(시설관리상태, 조경 및 경관, 공원 안전 성, 친절도) 중 가장 우선적으로 고려한 설계요소는 공원 안전성 $(\beta=0.276, p<.000)$ 임을 알 수 있었다. 공원안전성은 도시공원 의 이용자 만족도 중 지속적으로 관심을 받아온 중요 항목 중 하나로서 공원 안전성의 확보를 위하여 추후 도시공원의 설계 에서는 사각지대를 없애는 자연감시, 공원 출입을 자연스럽게 통제하는 자연접근통제, 주민의 영역성 강화, 공원으로서의 명 료성 강화, 행위 활성화, 지속적인 유지관리 등 범죄예방환경설 계 $(\mathrm{CPTED})$ 를 적용한 설계기법의 연구와 적용이 필수적인 요 소로 파악된다.

2. 조경 및 경관 $(\beta=0.230, p<.000)$ 은 공원 안전성에 이어 공 원이용 만족도에 영향을 끼치는 두 번째로, 중요한 요소로 인식 되었다. 도시공원의 유형 및 성격과 관계없이 어떤 도시공원이 든 수목으로 짜임새 있도록 구성되고 잘 관리되는 조경공간 및 경관이 요구됨을 알 수 있었다. 수경시설 및 수목, 그리고 다른 시설과의 조화 등 조경 및 경관에서 조사된 모든 세부항목이 공원의 이용만족도에 매우 큰 영향을 미치는 것으로 나타났으 며, 따라서 공원의 설계에서 적절하며 균형 있는 수경시설과 수목의 배치가 매우 중요한 요소로 판단된다.

3. 친절도 $(\beta=0.208, p<.000)$ 는 공원이용만족도 설문조사 결 과, 현재의 공원에서 가장 먼저 개선해야 되는 상황으로 나타 나고 있으나, 실제 공원이용만족도를 평가하는데 있어서는 다 른 요소들에 비해 직접적인 영향력이 크지는 않다고 판단된다. 공원 이용객의 만족을 위해서는 친절도 교육 등을 통하여 서비 스적 마인드를 갖게 하여 불만을 개선하고, 매점/음식점의 가 격 및 시설에 대한 관리도 필요한 것으로 판단되며, 이러한 친 절도 관련 요소들을 공원 설계의 단계에서 어떻게 더 나은 방 향으로 개선할 수 있을지에 대해 고민하고 이를 반영할 필요는 있으나, 필수 설계요소로서의 공원 안전성 및 조경 및 경관 요 소에 비해서는 중요성이 적은 것으로 판단된다.

새로이 만들어지거나 재정비되는 도시공원의 이용만족도를 보다 확대하고 실제 도시민들에게 필요한 공간으로서 도시공원 의 설계 방향성이 설정되어야 할 것이다. 이를 위해서 본 연구 에서는 도시공원의 필수 설계요소를 서울시 도시공원의 이용 만족도 조사를 바탕으로 추출하고자 하였다. 그러나 본 연구는 조사기간이 짧고, 다양한 공원유형에 대한 세분화된 데이터 분 석에는 미치지 못한 한계점을 지니고 있으며, 추후 보다 다양 한 설계요소에 대한 이용자 만족도를 계절별, 유형별 대단위조 사를 바탕으로 파악하여 보다 깊이 있는 설계요소의 추출이 이 루어져야 할 것이다.

\section{References}

1. Bae, M. K. and Y. R. Kim(2013) Development of urban park supply alternatives considering the equity evaluation of urban park service: Focused on Cheongju city. The Korea Spatial Planning Review 77: 49-66.

2. Bowerman, B. L. and R. T. O’Connell(1990) Linear Statistical Models: 
An AppliedApproach, 2nd ed. Duxbury, Belmont, CA

3. Cho, S. C. and M. H. Yeon(2014) A development of a safety checklist for children's park. Journal Korea Society of Visual Design Forum 43: 255-266

4. Im, S. B.(1991) A study on the developmental direction with reference to user's satisfaction of urban park: Cases study of Daeshin Natural Park in Pusan City. Journal of the Korean Institute of Landscape Architecture 19(3): 87-97.

5. Joo, S. H.(2008) Assessment of contemporary urban parks in Korea: satisfaction and landscape images. Journal of the Korean Institute of Landscape Architecture 36(4): 36-47.

6. Kaiser, H.(1974) An index of factorial simplicity. Psychometrika 39(1): 31-36.

7. Kang, Y. G.(2011) A study on the safety evaluation of urban parks. Journal of Community Safety and Security by Environmental Design 2(1): 1-17.

8. Kim, H. J., S. G. Jung and W. S. Lee(2011) Evaluation of supply adequacy of the urban park by spatial imbalance analysis. Journal of the Korean Institute of Landscape Architecture 39(4) : 18-27.

9. Kim, Y. G. (2014) A study on the distributive equity of neighborhood urban park in Seoul viewed from green welfare. Journal of the Korean Institute of Landscape Architecture 42(3): 76-89.

10. Kim, Y. I., J. K. Kim, J. S. Ahn and A. H. Choi(2010) Citizen satisfaction model for urban parks and greens: A transactional approach in the case of Anyang City, Korea. Journal of the Korean Institute of Landscape Architecture 38(3): 62-74.

11. Lee, D. H. and K. J. Lee(2010) A study on park service provision assessment in Busan metropolitan city. Journal of the Korean Association of Geographic Information Studies 13(1): 164-172.

12. Lee, H. Y.(2009) A study on the distributional property and utilizing behaviour of city parks in Gwangju. Journal of the Korean Urban Geographical Society 12(3): 27-40
13. Lee, J. J., S. C. Park and H. Kim(2009) A study on the effective plans to increase urban parks through activating private participation: Focusing on the plans to improve park facilities at the balance point of public and private interest. The Geographical Journal of Korea 43(4): 675-684.

14. Lee, J. S. and D. J. Lee(2009) Public safety comparative analysis for night park users(1994/2008). Journal of Environmental Science International 18(5): 551-559.

15. Matzler, K., F. Bailom, H. Hinterhuber, B. Renzl and J. Pichler(2004) The asymmetric relationship between attribute-level performance and overall customer satisfaction: A reconsideration of the importance performance analysis. Industrial Marketing Management 33(4), 271277.

16. Moon, C. H.(2001) A study on the spatial characteristics of urban parks in Seoul through the analysis of decisive factors about degree of users' satisfaction. Journal of Geographic and Environmental Education 9(1): 97-118.

17. Park. Y. J. and H. O. $\operatorname{Kim}(2010)$ A study on status of use of community park and level of satisfaction based on types of its facilities. Journal of the Environmental Sciences 4: 427-436.

18. Rho, J. H.(1995) Perception of public safety of night users in neighborhood parks. Journal of the Korean Institute of Landscape Architecture 23(2): 213-222.

19. Seo, J. H. and D. G. Kim(2000) An satisfaction degree analysis of programs in the city park: Tokyo metropolitan city parks, in Japan. Journal of the Korean Institute of Landscape Architecture 28(5): 58-67.

20. Won, Y. and Y. D. Jeong(2001) Analysis of the public safety by user's behavior of urban parks. Journal of Korean Society for Environmental Technology 2(1): 17-26.

21. Zeisel, J.(1981) Inquiry by Design: Tools for Environmental Research. Cambridge Univertsity Press. 68-137.

Received : 15 October, 2018

Revised : 25 November, 2018

Accepted : 25 November, 2018 3 인익명 심사필 